\title{
A Identidade e o Contexto Organizacional: Perspectivas de Análise
}

\author{
Hilka Vier Machado
}

\section{ResUMO}

Este artigo aborda a temática da identidade, apontando suas interfaces com o ambiente organizacional. Enquanto descreve diferentes níveis do fenômeno da identidade, apresenta delimitações para o estudo de cada categoria, assim como as possibilidades de integração entre elas e sua aplicabilidade aos estudos organizacionais. Assim, a partir da abordagem da identidade pessoal, da identidade social, da identidade no trabalho e da identidade organizacional, foram extraídas reflexões, que visam ampliar a discussão em torno da subjetividade nas organizações. Verificou-se que as perspectivas de estudo da identidade nas organizações são múltiplas e há ainda grande espaço para ser explorado.

Palavras-chaves: identidade; estudos organizacionais; organizações; trabalho.

\begin{abstract}
This paper has an approach about identity, showing its application to the organizational theory. While describe different levels of the identity phenomenon, the paper establishes the frontiers of the study among each category, as well the possibilities of integration among the different approaches and their applicability in the organizational studies. In this way, the personal identity, the social identity, the identity in the work and the organizational identity are categories discussed, whose goal is extending the discussion about the subjectivity in organizations. It was verified that the perspectives of identity's study in organizations are multiples and there is a large field for discussion.
\end{abstract}

Key words: identity; organizational studies; organizations; work. 


\section{INTRODUÇÃO}

O tema identidade tem sido bastante enfatizado em estudos relativos a fenômenos sociais contemporâneos. Tanto do ponto de vista pessoal, quanto social, a identidade é importante para melhor compreensão de práticas singulares ou coletivas, desencadeadas na atualidade.

Em nível pessoal, a identidade, ou o conceito de si mesmo, orienta a ação individual. No plano social, as identidades das pessoas configuram-se como a percepção de si mesmas dentro de um ou vários grupos, e, nesse sentido, direcionam os movimentos, refletindo a ação grupal.

No âmbito organizacional, os estudos sobre identidade, de modo geral, começaram a se desenvolver a partir do final da década de 80. Deste modo, devido à pouca tradição no desenvolvimento desses estudos, muitas vezes as abordagens sobre identidade não têm sido devidamente delimitadas.

Além disso, há que se considerar o impacto que o trabalho exerce sobre a conformação das identidades. Nesse sentido, a identidade no trabalho constitui também uma das ramificações da identidade nas organizações.

Assim, no contexto organizacional, sobrepõem-se constantemente interações do indivíduo com diferentes grupos, com o seu trabalho e com a organização, como fenômenos distintos. O que se observa, no entanto, é que, ao abordar a identidade no território organizacional em geral, os estudos raramente estabelecem a articulação necessária entre os planos mencionados, ou seja: o pessoal, o social e o organizacional.

Desse modo, o presente artigo pretende apresentar uma reflexão mais ampla sobre as perspectivas de análise da identidade no universo organizacional. A partir de uma revisão de estudos anteriores, identificam-se os seguintes campos de análise: identidade pessoal, identidade social, identidade no trabalho e identidade organizacional. Em seguida, apresentam-se as interrelações dos campos sugeridos, bem como os limites de estudo para cada uma das perspectivas abordadas. Finalmente, abordam-se possíveis implicações da identidade no espaço organizacional. 


\section{A Identidade em Estudo}

O estudo da identidade envolve múltiplos níveis de análise. No âmbito geral, dois níveis são mencionados nos estudos sobre essa temática: o pessoal e o social (Antaki e Widdicombe, 1998; Gioia, 1998; Ruano-Borbalan, 1998; Castells, 1999; Brown e Starkey, 2000; Howard, 2000). Essa é a primeira classificação a que normalmente os estudiosos do assunto recorrem para distinguir o fenômeno em seus níveis de percepção. A identidade pessoal está ligada a uma construção individual do conceito de si, enquanto a identidade social trata do conceito de si a partir da vinculação da pessoa a grupos sociais.

Nos estudos organizacionais, outras classificações têm demonstrado sua aplicabilidade. São os conceitos de identidade no trabalho (Sainsaulieu, 1977) e identidade organizacional (Whetten e Godfrey, 1998; Brown e Starkey, 2000; Gioia, Schultz e Corley, 2000; Pratt e Foreman, 2000; Scott e Lane, 2000).

Embora se estabeleça essa diferenciação para fins de estudo, há uma ligação entre as distintas formas estabelecidas, pois todas elas estão embasadas no comportamento de indivíduos ou grupos. Mesmo a identidade organizacional, que parece mais centrada nas organizações, só pode ser explicada a partir do comportamento humano nas organizações. Entretanto a distinção é importante para fins de análise, pois cada uma das classificações contém elementos próprios, que melhor possibilitam a sua compreensão. Nessa perspectiva, apresentam-se, a seguir, abordagens sobre cada um desses níveis e, na seqüência, suas interfaces, iniciando-se assim pelas considerações acerca da identidade pessoal.

\section{Identidade Pessoal}

A identidade constitui uma tentativa de explicação do conceito de si, sendo fruto de uma construção psicológica. É processo em construção, definido pela intermediação constante das identidades assumidas e das identidades visadas (Dubar, 1996). Essa distância existente entre tais tipos de identidades é exatamente o espaço de conformação do eu, ou seja, da construção da identidade. É sob esse espaço que vão se processar as interações sociais e ocorrerá a participação dos outros na construção da própria identidade.

A dinâmica da identidade é alimentada pela busca constante de unidade subjetiva por parte dos indivíduos, pois eles adotam freqüentemente padrões comportamentais direcionados para preencher as expectativas do outro sobre sua própria conduta, contrariando muitas vezes sua autodeterminação (Ricoeur, 1990). Entretanto, se essa dissonância ocorrer com muita intensidade, pode resultar 
em fragilidade e em ruptura da unidade subjetiva (Moessinger, 2000). Construir a própria identidade é, portanto, permanente desafio no sentido de encontrar o equilíbrio entre aquilo que se é e o que os outros esperam que nós sejamos. O outro é o espelho social que permite ao indivíduo reconhecer-se, avaliar-se e aprovar-se. Sob essa perspectiva, o eu não existe, a não ser em interação com os outros (Whetten e Godfrey, 1998).

Desse modo, embora exista em cada indivíduo um senso de individualidade, a construção do autoconceito é inseparável do outro; portanto as experiências de socialização constituem o principal referencial para formação das identidades. É por meio delas que os processos de identificação são deflagrados e os modelos são construídos no imaginário de cada um, fornecendo o suporte para o processo de internalização por parte daqueles que se identificam, porque a identificação "é a modelagem em pensamento, sentimento ou ação de um indivíduo sobre outra pessoa" (Symonds apud Sainsanlieu, 1977, p.305). Ao viver essas experiências, o indivíduo busca a noção de si, da presença subjetiva, na tentativa de definir as fronteiras de si, de preservá-las e de reencontrá-las. Nesse sentido, a identidade é resultante de múltiplas identificações (Maffesoli, 1998; Miranda, 1998).

Assim as estruturas identitárias encontram-se constantemente renovadas pelo seu caráter dinâmico e múltiplo, construídas e reconstruídas a todo o momento. Os sucessivos processos de socialização conferem à palavra eu o conteúdo de diversos eus (Craib, 1998), os quais o indivíduo procura constantemente ordenar.

A identidade é sobretudo uma luta entre o processo consciente e inconsciente. Os processos inconscientes ressoam no consciente, produzindo significados. A ausência dessa transferência produziria uma vida estéril, como uma concha vazia, e é somente por meio dela que a maturidade do indivíduo acontece (Chodorow, 1989). No momento em que ele organiza o inconsciente, a individuação torna-se mais forte e resulta na formação de um autoconceito mais diferenciado.

A memória exerce papel importante na construção da identidade, porque a representação de si é inseparável do sentimento de continuidade temporal. $\mathrm{O}$ passado, o presente e o futuro são importantes para prover continuidade ou consistência subjetiva (Haviland et al., 1994). A partir dos múltiplos mundos classificados, ordenados e nominados na memória, segundo a lógica do indivíduo e de sua categorização social, que consiste em reunir o que se parece e separar o que difere, o indivíduo vai construir sua própria identidade (Candau, 1998). Ao narrar seu autoconceito, o sujeito ordena, segundo sua autoridade, os eventos que ele selecionou, consciente e inconscientemente, e registrou na memória. Não só o passado, mas também o futuro age na conformação das identidades, por meio das representações desejadas de si, ou seja, da idealização do eu (Markus e 
Nurius, 1986). O self desejado é, desta forma, fonte de motivação para novas formas de identidade.

A identidade é ainda um fenômeno que se processa ao longo da vida do indivíduo, atuando como mecanismo regulador das interações sociais e da presença do outro na vida pessoal. Erickson (1994) atribui a formação da identidade a diferentes fases do ciclo de vida; para este autor, a infância e a adolescência são períodos nos quais a influência dos outros na definição das identidades é mais forte. $\mathrm{Na}$ idade adulta os espelhos que orientam as escolhas não estão tão disponíveis como na infância ou na adolescência; mas, mesmo assim, o indivíduo continua buscando referências, protótipos e modelos até atingir determinado nível de composição entre a sua interioridade e a exterioridade, que corresponde ao processo de individuação. No entanto o nível de interioridade nunca será pleno, pois algum nível de interação social será sempre necessário que exista.

O conceito de si é, portanto, uma construção mental complexa, fruto de uma relação dialética que considera o indivíduo igual a seus pares, mas único na sua existência, na sua experiência e vivência pessoal. A igualdade e a diferença permeiam a todo o momento as tentativas de auto-representação por parte dos indivíduos. Assim uma identidade bem construída é aquela que delineou os limites entre a individualidade e os grupos aos quais a pessoa está vinculada. O resultado é que, embora reunidos na presença física, o eu e o grupo se encontram separados nos processos psíquicos.

\section{Identidade Social}

A identidade social é "a representação que um indivíduo dá a si mesmo por pertencer a um grupo" (Tajfel apud Whetten e Godfrey, 1998). Nesse sentido, ela é o fruto da interação dos mecanismos psicológicos e dos fatores sociais. Trata-se de processo social dinâmico, em contínua evolução, que se constrói por semelhança e oposição.

A identidade de um grupo repousa sobre uma representação social construída, sobre a qual uma coletividade toma consciência de sua unidade pela diferenciação dos outros (Dubar, 1996), pois a vida no grupo cria um imaginário social (Maffesoli, 2000). Dessa forma, a identidade social é constituída não somente pela representação que o indivíduo faz dele mesmo no seu ambiente social, referindose a diferentes grupos aos quais ele pertence, mas também aos grupos de oposição, aos quais ele não pertence (Zavalloni apud Chauchat e Durand-Delvigne, 1999), pois essa identidade é guiada pela necessidade do indivíduo de ser no mundo, assim como pela sua necessidade de pertencer a grupos sociais. Isso ocorre porque a definição do outro e de si mesmo é largamente relacional e comparativa (Ashforth e Mael, 1989). 
Pertencer a um grupo representa para o indivíduo uma possibilidade de redução da incerteza subjetiva (Hogg e Terry, 2000), pois o significado emocional implícito na relação entre eles constitui, para o sujeito, um estímulo afetivo, na medida em que ele se sente integrante do grupo. Não só o sentimento de pertencer, mas também a sua autopercepção como membro do grupo são as bases requeridas para a identificação social, propiciando assim uma orientação para a ação, compatível com a sua participação no grupo. A adesão ao grupo requer, portanto, pensar, agir e sentir-se como integrante, a fim de que todos tenham em comum uma mesma lógica de atuar nas posições sociais que ocupam (Sainsanlieu, 1977).

A representação de um grupo é comum, porque deriva de histórias vividas em conjunto e de saberes comuns. As crenças constituem a característica mental de um grupo e exprimem a experiência comum de seus membros (Deschamps et al., 1999). Elas orientam a escolha dos meios e dos fins para as ações particulares e servem de critério de avaliação de acontecimentos. Elas contribuem também para estabelecer as fronteiras simbólicas do grupo (Cuche, 1996). São elas também que colaboram para consolidar a unidade do grupo, a qual é também definida por elementos como o tamanho e a diversidade (McGarty apud Sherman, 1999). É por meio do interacionismo, que consiste na premissa de que as pessoas atribuem um significado simbólico a objetos, comportamentos, pessoas e outros, que é desenvolvido e transmitido pela interação dos membros (Howard, 2000), que o grupo assegura a sua coesão. Dessa forma, o grupo constitui a imagem de uma totalidade unificada; a identidade social resulta na sua unidade e no processo de identificação e distinção, pelo qual cada um procura fundar sua coesão e marcar sua posição em relação a outros grupos.

A identidade social é, portanto, "um processo de justaposição na consciência individual, uma totalidade dinâmica, em que os diferentes elementos interagem na complementaridade ou no conflito, pois o indivíduo tende a defender sua existência e sua visibilidade social, sua integração à comunidade, ao mesmo tempo que ele se valoriza e busca sua própria coerência" (Lipianski apud Ruano-Borbalan, 1998, p.144).

Em consonância com a Teoria da Identidade Social, os indivíduos (Tajfel e Turner apud Worchel e Austin, 1986):

- sempre procuram manter uma identidade social positiva;

a identidade social positiva está ligada à comparação positiva que o indivíduo faz de grupos aos quais se vincula;

- quando a identidade social for insatisfatória, o indivíduo abandona o seu grupo e busca vinculação em outros grupos. 
Como resultado desse processo, o indivíduo sacrifica sua vida pessoal, liberdade e recursos pessoais por grupos que se tornam centrais na sua identidade (Worchel, 1998). A categorização dos indivíduos pode ocorrer, então, por diferentes finalidades e, deste modo, eles fazem normalmente parte de vários grupos, os quais fornecem múltiplas bases para a categorização de si em diferentes momentos (Sherman et al. apud Abrams e Hogg, 1999).

Algumas classificações dos grupos assim os distinguem: (1) grupo primário, como sendo estável, caracterizado por uma vida comum, relações pessoais e íntimas entre seus membros; (2) grupo secundário, no qual os indivíduos são motivados por um objetivo determinado e suas relações são formais e funcionais (Lipiansky apud Ruano-Borbalan, 1998). O mesmo autor apresenta outra distinção: (1) grupos de vinculação, como aqueles de que o indivíduo faz parte e; (2) grupos de referência, aqueles que fornecem valores, normas e modelos de atitude, de opinião e comportamento a seus membros.

Por outro lado, Lipiansky (apud Ruano-Borbalan, 1998) salienta que a identidade social não é somente constituída pelos traços positivos que o indivíduo assinala nos grupos, mas também pelos negativos, que precisam ser evitados. Estes caracterizam a identidade negativa, projetada sobre o outro (o inimigo, o estrangeiro etc), "o que permite purificar, unificar e confortar a comunidade, evitando os elementos que ameaçam a sua coesão social" (Ruano-Borbalan, 1998, p.146). Dessa forma, a violência e formas de contestação podem acompanhar certos casos de afirmação identitária. Este autor ressalta que grupos que se opõem podem influenciar-se mutuamente, num processo de "aculturação antagonista".

Grosso modo, a identidade social se funda sob determinadas categorias, como, por exemplo, a etnia, a identidade sexual, a classe social, os portadores de deficiências, a idade, entre outras. Unidos sob o mesmo fundamento, os indivíduos procuram sua contextualização no tempo e no espaço, buscando fortalecer suas identidades. Por essa razão é que as manifestações ligadas a nacionalismos e a movimentos sociais se processam num dado contexto de construção social das identidades, que a todo o momento são construídas e desconstruídas. Por isso a identidade social é também associada a bases de poder (Deetz, 1994; Antaki e Widdicombe, 1998).

Resumidamente, o conceito de identidade social articula o processo cognitivo de categorização e vinculação social e é "a estrutura psicológica que realiza a ligação entre o indivíduo e o grupo" (Baugnet, 1998, p.66). Ela é importante, pois haverá sempre uma ligação entre a experiência afetiva oriunda dos relacionamentos e a experiência cognitiva da descoberta de um sentido ao mundo, às coisas e à ação. 


\section{Identidade no Trabalho}

Baugnet (1998) salienta que, pelo exercício de papéis, os indivíduos constroem ativamente suas identidades. Na mesma direção, os papéis ligados ao mundo do trabalho compõem uma face da estrutura identitária dos indivíduos e, de acordo com Sainsanlieu (1995), a empresa constitui um lugar de socialização importante para os indivíduos que nela trabalham. "Ela é uma verdadeira instituição secundária de socialização, a qual, após a escola e a família, modela atitudes, comportamentos, a ponto de produzir uma identidade profissional e social" (Sainsanlieu, 1995, p.219).

A socialização dos indivíduos no mundo do trabalho é fruto da experiência das relações de poder, vivenciadas no universo produtivo, as quais geram normas coletivas de comportamento e fornecem a possibilidade de construir uma identidade no trabalho, entendida como: "a maneira de elaborar um sentido para si na multiplicidade de papéis sociais, e de fazê-la ser reconhecida por seus companheiros de trabalho" (Sainsanlieu, 1995, p.217).

De acordo com Sainsanlieu (1995), as identificações possíveis por parte do indivíduo na organização estão vinculadas: (1) ao trabalho que realiza, sendo que quanto mais intensa, maior a probabilidade de resultar em progressão profissional; (2) com a empresa, e, nesse caso, o resultado é um sentimento de proteção por parte do indivíduo; (3) com uma trajetória, constituindo uma identidade visada, pautada num projeto pessoal que o indivíduo imagina para si no trabalho, ou seja, sua possível identidade. Segundo o autor, são também importantes na construção das identidades no trabalho os tipos de relacionamentos, aos quais o indivíduo está submetido na empresa, geralmente mantidos numa hierarquia entre colegas ou com outras pessoas na empresa. Além desses fatores, os sistemas de representação existentes nas empresas são variáveis importantes no processo de constituição das identidades na esfera organizacional. Para Sainsanlieu (1995) as representações ligadas à legitimação da autoridade na empresa, aquelas ligadas às finalidades do trabalho e da empresa, estão entre as diretamente relacionadas com o autoconceito no trabalho.

O tipo de relações de trabalho e de poder que é mantido no universo empresarial influencia sobremaneira a construção de identidades. Assim, ao estudar a identidade em um ambiente com estrutura hierárquica rígida, Sainsanlieu (1977, p.334) observou que "nas circunstâncias de total dependência e de incapacidade de se opor aos outros, colegas ou chefes, os indivíduos não podem senão interpretar sua experiência de trabalho de maneira imaginária, alucinatória e fantasmagórica". Ele verificou também que havia uma tendência dos indivíduos em se diferenciarem de seus inferiores e se identificarem com seus superiores, numa tentativa de reduzir a sua distância social. Para ele, esse tipo de identificação com os mais 
poderosos pode ser ainda interpretada como produto de uma avaliação permanente dos meios, de que o indivíduo dispõe para se engajar no combate à ordem estabelecida, sustentando a sua diferença no sistema social no qual se insere. No entanto "esses processos são entraves para o avanço e a igualdade entre pares, em face da tentação permanente do favoritismo" (Sainsanlieu, 1977, p.310), que pode se estabelecer entre os membros da organização, na tentativa de reduzir as desigualdades e dissonâncias.

A identidade no trabalho também se processa no plano afetivo e cognitivo. $\mathrm{O}$ fato de viver sob uma estrutura institui uma espécie de mentalidade coletiva, com a qual o indivíduo se conforma, assimilando suas regras e normas de comportamento e estabelecendo vínculos afetivos com as pessoas com as quais convive nesse ambiente. Esse processo pode derivar em identificações por parte do indivíduo, as quais podem conter significados distorcidos. Sobretudo quando os espaços de autonomia do indivíduo na organização são reduzidos, há a possibilidade de engendrar processos de identificação que tenham natureza projetiva, nos quais o indivíduo se imagina no lugar do outro, buscando assim a destituição do lugar ocupado, ou os de natureza introjetiva e imitativa, quando o indivíduo copia o outro e procura viver a vida do outro.

Ao analisar a identidade no trabalho, especialmente em modelos organizacionais com predomínio de modernas relações de trabalho, os quais pressupõem uma certa autonomia dos indivíduos, Sainsanlieu (1995) constatou que há pluralidade de modelos identitários no universo do trabalho, que se distinguem principalmente pelos tipos de socialização compartilhada entre os indivíduos e por seus modos de integração na empresa. Essa variedade de lógicas implica a possiblidade de existirem várias maneiras de se definir com relação às situações de trabalho e, portanto, diversos tipos de motivação afetam os indivíduos. Ele classificou seis modelos identitários, ordenados sob a variável coerência identitária, passando de variável, fraca a extremamente forte nos seguintes tipos, respectivamente: (1) regulamentar; (2) comunitário; (3) profissional; (4) profissional de serviço público; (5) temporário; e (6) empreendedor.

No ambiente de trabalho, tanto a identidade pessoal como a social pode ser construída, de acordo com as modalidades concretas de experiência. Assim,

"quando os meios de ser reconhecido como autor do resultado do trabalho não são acessíveis senão em nível coletivo, porque cada um é muito fraco para sustentar sozinho uma relação de desafio, a racionalidade não é acessível senão ao preço de certo grau de fusão entre os desejos realizados por meio dos processos de identificação projetiva recíproca entre os pares. Quando, enfim, cada um dispõe de meios suficientes para obter sozinho o reconhecimento de suas ações pelos outros, o indivíduo pode conciliar 
por ele mesmo o desejo, a reflexão e a ação, a ponto de edificar uma lógica pessoal e particular" (Sainsanlieu, 1995, p.335).

A construção das identidades no trabalho não está desvinculada dos interesses pessoais e coletivos, que estão sendo constantemente articulados nas organizações. Os arranjos sociais que se desdobram nas empresas são dinâmicos e permeiam a memória dos seus integrantes. Os indivíduos selecionam, assim, aqueles relacionamentos que constituirão parte de seu universo relacional, para que, a partir daí, construam as experiências e os relacionamentos com os quais irão fazer face às pressões que objetivam elevar os espaços de poder na organização. A identidade no trabalho constitui, dessa forma, componente importante no processo motivacional, que concorre também para a construção de uma autoestima positiva. Conseqüentemente, não só a realização do trabalho, mas também a esfera social organizacional é positivamente afetada, podendo resultar em formas de trabalho mais criativas, que contribuem para integrar a subjetividade, a socialização e o trabalho.

Não resta dúvida de que a força dos processos de categorização na organização contribuirá para maior solidificação da identidade no trabalho, porque eles resultam em sentimentos de vinculação e diferenciação, que favorecem uma visão simbólica de si como integrante de um espaço imaginário maior na organização. Nessa atmosfera, simultaneamente, acontece um fenônemo que liga psiquicamente o indivíduo à organização, ou seja, a identidade organizacional.

\section{Identidade Organizacional}

Outro desdobramento nas pesquisas sobre identidade trata da identidade organizacional. Os trabalhos dessa natureza são relativamente recentes na teoria organizacional; contudo os resultados têm demonstrado a sua aplicabilidade no referido campo, incluindo desdobramentos que associam a identidade a outras variáveis de estudo. De modo geral, o pressuposto que baseia essa área é que as organizações e seus grupos são categorias sociais e, portanto, existe em seus membros a percepção de que são membros dela. De forma significativa, portanto, as organizações existem na mente de seus membros e a identidade organizacional é parte da identidade individual deles. As necessidades e comportamentos são coletivos e a ação dos membros da organização é influenciada por suas autoimagens organizacionais (Brown, 1997).

A identidade organizacional compreende o processo, atividade e acontecimento por meio dos quais a organização se torna específica na mente de seus integrantes (Scott e Lane, 2000). Esse processo compreende as crenças partilhadas pelos membros da organização sobre o que é central, o que a distingue e é duradouro 
na organização (Albert e Whetten apud Whetten e Godfrey, 1998). Ele se constrói, dia após dia, quando o indivíduo vai internalizando a crença de que a organização na qual está inserido é a mesma que era ontem, simbolizando a sua existência temporal. Nessa perspectiva, Machado-da-Silva e Nogueira (2001), ao estudarem a identidade organizacional de duas organizações, procuraram destacar os seus aspectos distintos e duradouros, para interpretarem, a partir deles, as referidas identidades. Também Albert e Whetten (apud Whetten, 1998) ressaltam que a identidade organizacional tem três dimensões: (1) a definida pelos membros da organização, que é a central; (2) o que distingue a organização de outras; e (3) o que é percebido como traço contínuo, ligando o passado ao presente.

A representação da organização é expressa por seus membros por meio de comportamentos, comunicação e simbolismo. A idealização e a fantasia também fazem parte desse processo e explicam a tendência de as pessoas se identificarem com as organizações, principalmente quando elas representam uma possibilidade de conexão com seus atributos e desejos pessoais. Nesse sentido, a identificação com a organização tem uma associação linear e positiva com a realização de desejos (Mael e Ashforth, 1992). Entretanto os objetivos, a missão, as práticas e os valores presentes na organização também contribuem para dar forma às identidades organizacionais, diferenciando uma da outra, aos olhos dos seus integrantes (Scott e Lane, 2000).

Para Jo Hatch e Schultz (1977, p.361) a identidade organizacional é "o produto reflexivo do processo dinâmico da cultura organizacional". A cultura provê o material simbólico com o qual as imagens serão construídas e comunicadas. Ao correlacionar cultura, identidade e imagem, os autores sustentam que a experiência de trabalho dos participantes da organização e a visão da capacidade de liderança dos níveis estratégicos da organização são os elementos determinantes. Todavia para os autores a identidade organizacional sofre também influências externas, por meio do processo de formação de imagens.

Embora exista distinção entre identidade e imagem organizacional, esta última é nitidamente relacionada com a formação da identidade organizacional. Enquanto a identidade é associada à visão interna na empresa, a imagem está ligada também a uma visão externa. Por isso qualquer deterioração da imagem pode constituir um risco para a identidade organizacional. Por outro lado, a imagem está associada à identidade corporativa (Gioia, Schultz e Corley, 2000). Para Rindova e Schultz (apud Whetten e Godfrey, 1998) existe uma complementaridade entre a identidade organizacional e a identidade corporativa, que permite conjugar as percepções interna e externa da organização. Nesse sentido, a identidade corporativa é freqüentemente chamada de identidade visual, pois se utiliza de formas visuais; a identidade organizacional é formulada e expressa por meio da palavra. A primeira 
tem foco na externalidade e nas percepções do mercado; a última tem foco interno nas crenças dos membros da organização. Além disso, a identidade organizacional cria um senso de identificação entre os membros da organização, enquanto a identidade corporativa estimula a diferenciação da empresa no mercado. Esses elementos caracterizam um processo circular, que envolve dependência mútua entre cultura, imagem e identidade (Rindova e Schultz apud Whetten e Godfrey, 1998).

As associações entre cultura e identidade têm permeado estudos na esfera organizacional, tais como o de Pavlica e Thorpe (1998), que estudaram a autopercepção gerencial comparativa entre gerentes da República Tcheca e da Grã Bretanha e o de Belle (1991), associando identidade profissional, gênero e cultura de empresa. Outra comparação presente nos estudos sobre identidade no âmbito organizacional, é aquela ligada à ideologia corporativa, como uma das formas de construção da identidade organizacional. Sob esse aspecto, destacam-se os estudos sobre a crise identitária de gerentes intermediários em contextos de reestruturação organizacional (Rouleau, 2001; Turnbull, 2001).

No âmbito organizacional a identidade pode apresentar diferentes configurações. Albert e Whetten (apud Pratt e Foreman, 2000) apresentam os seguintes tipos de identidades: (1) ideográfica, quando não há uma unidade sobre a identidade da organização; conseqüentemente diferentes grupos, subgrupos e unidades da organização mantêm múltiplas identidades; (2) holográfica, isto é, múltiplas identidades são compartilhadas por todos na organização. Para Pratt e Foreman (2000) múltiplas identidades organizacionais podem ser gerenciadas, resultando até mesmo em vantagens para as organizações, como, por exemplo, a maior possibilidade de satisfazer as expectativas de seus membros, melhorar a sua capacidade de criatividade e aprendizado, além de facilidade em reter mão-deobra diversificada. Outro aspecto é ponderado por Asforth e Mael (1996), que consideram as identidades organizacionais como flexíveis e mutáveis. Elas podem passar de positivas a negativas ou vice-versa, dependendo dos acontecimentos, resultados e impactos das empresas.

Ao discutir a identidade organizacional, a identificação está presente, pois não há identidade sem identificação. A identificação organizacional constitui "um envolvimento baseado no desejo de afiliação" (Kelman's apud Ashforth e Mael, 1989, p.23). Essa identificação é, por vezes, utilizada como sinônimo de compromisso, embora ela seja mais internalizada do que este e possa engendrar aderência a valores e normas grupais, assim como homogeneidade de atitudes e comportamentos. Uma identificação forte com a organização "aumenta a cooperação entre os membros e a competição com os não membros" (Dutton, Dukerich e Harquail, 1994). Estes autores salientam que a identificação 
organizacional pode ter efeitos positivos e negativos sobre o autoconceito dos membros da organização. Nesse sentido, Ashforth e Mael (1989) chamam a atenção para a identificação cega, que pode se tornar problemática para a instituição ou para o equilíbrio de seus integrantes. Um processo intenso de identificação é discutido por Pratt (2000) que, ao relatar o caso da Amway, demonstra como a identificação é construída sob identidades projetadas, principalmente em termos de aspirações pessoais. "Os sonhos são considerados centrais para ser membro da família" (Pratt, 2000, p.465). Eles constituem o elo mental de ligação entre os membros e a companhia, numa tentativa de vinculação e de ratificação do desejo de afiliação, na medida em que a realização dos desejos está ligada à vinculação organizacional. Pratt (2000) ilustra também outras estratégias que visam a: (1) reduzir o círculo de relacionamentos de seus integrantes à esfera da companhia; e (2) categorizar as pessoas em termos ambivalentes como membros da Amway ou não.

A identidade organizacional, tal como as outras modalidades da identidade, remete ao vivido e à subjetividade. Ela orienta a ação dos indivíduos e é dinamicamente construída por meio de interações sociais, identificações e afiliações. Portanto o contexto identitário no âmbito organizacional é constituído pelo indivíduo, pelo grupo e pela organização. A fim de articular a discussão em torno dos níveis apresentados, aborda-se a seguir uma integração entre os tipos de identidade discutidos neste trabalho.

\section{Distinçăo e Integraçăo entre os Níveis de Análise}

Os níveis de identidade considerados até o momento, estão ligados à formação do autoconceito por parte dos indivíduos e resultam em influências na esfera pessoal, social, assim como no âmbito organizacional. Isso significa que há multiplicidade de identidades construídas simultaneamente, o que contribui para a complexidade do fenômeno em estudo. É possível, no entanto, delinear alguns limites entre cada categoria, para visualizar os impactos de cada uma delas. No Quadro 1 procurou-se reunir os aspectos principais de cada um dos tipos de identidade discutidos, evidenciando as diferenças de enfoque para cada abordagem. Embora todos os níveis estejam centrados na conformação do eu, esta se processa em diferentes maneiras, bem como em diferentes momentos da vida do indivíduo. Também a multiplicidade de relacionamentos está presente em todas as identidades e consiste um elemento importante para sedimentar os processos cognitivos e afetivos, indispensáveis para uma coerência identitária. 


\section{Quadro 1: Distinções entre Níveis de Estudo da Identidade}

\begin{tabular}{|c|c|c|c|c|c|}
\hline $\begin{array}{l}\text { Tipo de } \\
\text { identi- } \\
\text { dade }\end{array}$ & $\begin{array}{l}\text { Objeto de } \\
\text { estudo }\end{array}$ & $\begin{array}{l}\text { Meios de } \\
\text { construção }\end{array}$ & $\begin{array}{l}\text { Período de } \\
\text { ocorrência }\end{array}$ & $\begin{array}{l}\text { Espaços de } \\
\text { construção }\end{array}$ & Finalidades \\
\hline Pessoal & $\begin{array}{l}\text { A construção do } \\
\text { auto-conceito ao } \\
\text { longo da vida do } \\
\text { indivíduo. }\end{array}$ & $\begin{array}{l}\text { Diversos } \\
\text { relacionamentos } \\
\text { sociais, em } \\
\text { diferentes } \\
\text { esferas, bem } \\
\text { como } \\
\text { desempenho de } \\
\text { papéis. }\end{array}$ & $\begin{array}{l}\text { Permanente, } \\
\text { ocorrendo em } \\
\text { todas as fases da } \\
\text { vida. }\end{array}$ & $\begin{array}{l}\text { Múltiplos } \\
\text { relacionamentos } \\
\text { e papéis. }\end{array}$ & $\begin{array}{l}\text { Conformação } \\
\text { do eu, em } \\
\text { direção ao } \\
\text { processo de } \\
\text { individuação. }\end{array}$ \\
\hline Social & $\begin{array}{l}\text { A construção do } \\
\text { auto-conceito } \\
\text { pela vinculação a } \\
\text { grupos sociais. }\end{array}$ & $\begin{array}{l}\text { Interação a } \\
\text { grupos sociais } \\
\text { com finalidades } \\
\text { diversas. }\end{array}$ & $\begin{array}{l}\text { Permanente na } \\
\text { vida do } \\
\text { indivíduo. }\end{array}$ & $\begin{array}{l}\text { Múltiplos } \\
\text { grupos. }\end{array}$ & $\begin{array}{l}\text { Orientar e } \\
\text { legitimar a } \\
\text { ação, por } \\
\text { meio do } \\
\text { reconheci- } \\
\text { mento e da } \\
\text { vinculação } \\
\text { social. }\end{array}$ \\
\hline $\begin{array}{l}\text { Identidade } \\
\text { no traba- } \\
\text { lho }\end{array}$ & $\begin{array}{l}\text { A construção do } \\
\text { eu pela atividade } \\
\text { que realiza e } \\
\text { pelas pessoas } \\
\text { com as quais tem } \\
\text { contato no } \\
\text { trabalho. }\end{array}$ & $\begin{array}{l}\text { Interação com a } \\
\text { atividade e com } \\
\text { as pessoas no } \\
\text { trabalho. }\end{array}$ & $\begin{array}{l}\text { Na juventude, } \\
\text { na idade adulta } \\
\text { até a } \\
\text { aposentadoria. }\end{array}$ & $\begin{array}{l}\text { Múltiplas } \\
\text { atividades e } \\
\text { grupos } \\
\text { profissionais. }\end{array}$ & $\begin{array}{l}\text { Contribuir } \\
\text { para a } \\
\text { formação da } \\
\text { identidade } \\
\text { pessoal e } \\
\text { atuar como } \\
\text { fator } \\
\text { motivacional. }\end{array}$ \\
\hline $\begin{array}{l}\text { Identidade } \\
\text { Organiza- } \\
\text { cional }\end{array}$ & $\begin{array}{l}\text { A construção do } \\
\text { conceito de si } \\
\text { vinculado à } \\
\text { organização na } \\
\text { qual trabalha. }\end{array}$ & $\begin{array}{l}\text { Interação com } \\
\text { uma instituição } \\
\text { (com seus } \\
\text { valores, } \\
\text { objetivos, } \\
\text { missão e } \\
\text { práticas). }\end{array}$ & $\begin{array}{l}\text { A partir da } \\
\text { juventude, } \\
\text { enquanto estiver } \\
\text { vinculado a } \\
\text { alguma } \\
\text { instituição. }\end{array}$ & $\begin{array}{l}\text { Pode ocorrer em } \\
\text { uma ou em } \\
\text { múltiplas } \\
\text { organizações. }\end{array}$ & $\begin{array}{l}\text { Incorporar as } \\
\text { instituições } \\
\text { no } \\
\text { imaginário, } \\
\text { de forma a } \\
\text { orientar a } \\
\text { ação nessas } \\
\text { organizações. }\end{array}$ \\
\hline
\end{tabular}

Por outro lado, se cada um dos níveis apresenta suas particularidades no processo de definição da identidade, há profunda complementaridade entre eles, resultando que a formação da identidade pessoal, por meio do grupo, do trabalho ou da organização envolve a todo o momento construção e desconstrução, pois o contexto social é dinâmico e complexo. Desse modo, a formação do autoconceito, englobando a noção de grupo, incorporando o trabalho e as organizações, alicerça-se em etapas gradativas, construídas sobre processos de identificação, originalidade e conformação, os quais são permeados pela emoção e pela cognição, conforme demonstra a Figura 1. Dessa maneira, o indivíduo identifica-se com o grupo ou grupos aos quais pertence, com o trabalho que realiza e com a organização à qual pertence. Também esses elementos interagem na configuração da auto-representação do indivíduo. Além disso, a organização é o reflexo do trabalho realizado em seu interior e dos grupos que a constituem. $\mathrm{O}$ grupo ou grupos podem ser 
conhecidos pelo retrato do trabalho que realizam; o trabalho, por sua vez, também engloba o imaginário do grupo.

Figura 1: Integração entre Níveis de Estudo da Identidade

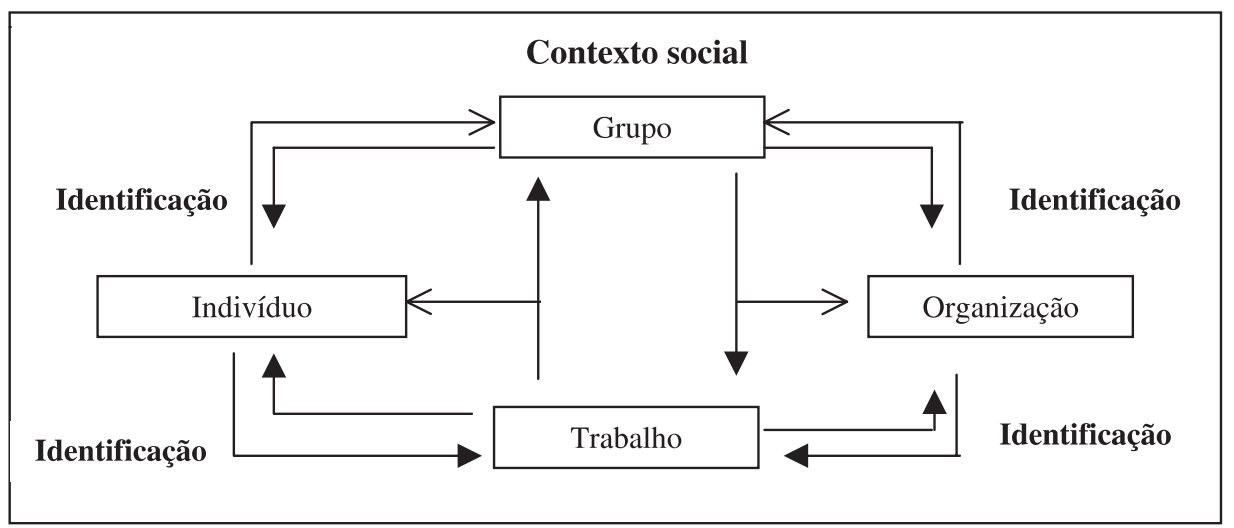

Ao analisar a identidade no contexto organizacional é importante considerar que o agir e o interagir dão forma às identidades. A todo o momento, portanto, realizar e pertencer são condições para que os processos de identificação sejam desencadeados e gerem estímulos, novas descobertas e maneiras de realizar as atividades, transformando o espaço organizacional em importante palco para potenciação das existências. Desse modo, o grupo, o trabalho e a organização passam a constituir as bases centrais de representação do eu para o indivíduo. Por último, é importante salientar que, quanto maior o reconhecimento do indivíduo em todos os âmbitos, ou seja, no trabalho realizado, no grupo ou na organização à qual o indivíduo está vinculado, maior é a força desses elementos na construção do conceito de si. Do ponto de vista organizacional, isso implica um ambiente de trabalho favorável, no qual seus integrantes manifestam autonomia e segurança na realização de suas tarefas. Outras implicações organizacionais são discutidas a seguir.

\section{IMPLICAÇÕEs PARA Estudos Organizacionais}

O campo de estudos sobre identidade na esfera organizacional revela-se amplo e fecundo. As possibilidades de conhecer a realidade social da organização a partir do estudo das identidades, são também formas importantes para compreender a estruturação da ação nesse ambiente, pois as identidades têm também o papel de estruturar a ação, por parte de indivíduos, grupos ou organizações. 
Alguns estudos, mencionados no decorrer do texto, estabeleceram importantes associações, como, por exemplo, sobre os efeitos da identidade social na produtividade de grupos (Worchel, 1998), da associação entre identidade organizacional e identidade corporativa (Rindova e Schultz apud Whetten e Godfrey, 1998; Gioia, Schultz e Corley, 2000) ou da associação entre a subjetividade e a identidade no trabalho (Sainsanlieu, 1977, 1995).

Ainda assim, há um campo vasto a ser explorado no que tange às configurações da identidade no meio organizacional e suas possíveis associações. Por exemplo, a existência de uma associação entre tempo de trabalho, identidade organizacional e identidade pessoal. Nessa perspectiva, ao realizar um estudo com aposentadas que se tornaram empreendedoras, Machado (1999) constatou que, para aquelas mulheres que trabalharam durante muitos anos na mesma instituição, a organização era uma referência muito forte em suas identidades pessoais e a ação empresarial nas empresas que criaram, estava intensamente ligada às orientações e valores adquiridos na experiência organizacional anterior. Ao mencionar a organização em seus discursos, as mulheres a referenciavam como um grupo primário de sua socialização, na medida em que, a todo o momento, estabeleciam associações entre a empresa, a figura materna ou paterna.

Outro aspecto ainda pouco explorado nos estudos desta natureza, está relacionado com a possibilidade de associação entre stress e identidade no trabalho. Não se sabe até que ponto níveis elevados de identidade no trabalho resultam em alta dedicação, que pode conduzir ao stress, ou se o exercício de um trabalho ao qual o indivíduo não se identifica contribui para o stress no trabalho.

É provável que uma elevada categorização social favoreça a coesão grupal na esfera organizacional; no entanto pouco foi explorado sobre a relação entre essa categorização social e a construção de uma identidade organizacional ou até mesmo com a identidade no trabalho. Além disso, em contextos de mudança organizacional, a categorização social exerce, certamente, considerável influência.

Outra associação importante foi estabelecida por Davel e Machado (2001) entre a liderança e a identificação nas organizações contemporâneas. Trata-se de uma abordagem da liderança alicerçada sobre questões políticas, cognitivas e emocionais, envolvendo constantemente reconhecimento e consentimento. Esse enfoque de estudos demonstra que a identidade e a liderança são fenômenos a serem estudados em conjunto, principalmente no ambiente de trabalho atual, orientado para a valorização da autonomia do indivíduo e do trabalho em grupo.

Enfim, essas reflexões fortalecem a premissa de que o contexto sociopsíquico é, em grande parte, determinante da vida organizacional e a identidade é um instrumento útil para melhor compreender a realidade organizacional. 
Especificamente, ao abordar a identidade, a principal das implicações aqui presente é a compreensão de que ela é fonte importante de estruturação da ação, sob qualquer das múltiplas perspectivas: o indivíduo, o grupo ou a organização. Embora níveis de estudos da identidade se sobreponham, há uma forma distinta de construir o autoconceito nos diversos planos: pessoal, no grupo, no trabalho e na empresa. Todavia, no plano imaginário, eles se encontram interligados e orientam a atuação do indivíduo.

Reconhecer a importância da identidade no âmbito das organizações, procurando a conjugação dos diferentes níveis de sua análise, implica a tendência em: (1) contribuir para ampliar a autonomia e a segurança da ação individual nas organizações; (2) estimular o trabalho em grupo, cooperativo e engendrado sob uma lógica consentida; (3) estimular a criatividade, resultante da experiência afetiva no trabalho; (4) favorecer o comportamento participativo nas organizações, na medida em que ele resulta da integração simbólica existente entre o indivíduo, o grupo e a organização.

Ao buscar a unidade, a partir da diferenciação, a identidade é capaz de harmonizar a igualdade e a soberania, na medida em que parte sempre do pressuposto de que somos iguais, mas únicos. Sob essa perspectiva, é possível articular o movimento de indivíduos, grupos e organizações em direção à integração e à autonomia.

\section{Conclusão}

Este trabalho abordou a identidade no contexto das organizações, a partir dos seguintes desdobramentos: o indivíduo, o grupo, a organização e o trabalho. Não obstante os diferentes níveis de análise, a perspectiva de um fenômeno integrado foi mantida.

Como processo único, foi possível verificar a sua abrangência no ambiente organizacional. De fato, classificar a identidade para fins de estudo, contribuiu para o entendimento mais detalhado do processo, ao mesmo tempo que permitiu visão mais ampliada. Nesse aspecto, é importante ressaltar que a abrangência da identidade não se restringe aos limites internos da organização, mas também ao externo, especialmente nos casos associados à imagem ou identidade comparativa, mencionados no decorrer do texto.

No contexto organizacional, a identidade é fenômeno psicossocial relevante e importante para estruturar a ação e a identificação é inerente à sua formação. 
Não há identidade sem identificação. Desse modo, o sentimento de identificação do indivíduo com a organização atua como fonte simbólica de proteção, desencadeando processos emocionais, que tendem a contribuir para a criatividade no trabalho; no entanto uma identificação muito intensa pode resultar em interferência negativa na construção da identidade porque, para uma identidade estar bem consolidada, é necessário que exista uma fronteira simbólica entre o eu, o grupo, o trabalho e a organização.

Outro ponto importante a ser mencionado é que nem sempre existe articulação perfeita entre os diferentes focos de análise sugeridos. Logo a formação das identidades no plano pessoal, social, no trabalho e organizacional, segue, muitas vezes, diferentes estágios em seus ciclos. Essa relação entre as identidades pode representar um campo de pesquisa promissor. Nesse sentido, como ressaltam Whetten e Godfrey (1998), o enfoque qualitativo em estudos sobre identidade pode contribuir para ampliar a compreensão do fenômeno.

Finalmente, este estudo não visou a restringir o debate em torno desta temática, mas contribuir para uma reflexão ampliada em torno de um processo complexo e abrangente, que é a identidade no contexto organizacional.

\section{Referências Bibliográficas}

ABRAMS, D.;

HOGG, M.

Social identity and social cognition. London: Blackwell Publishers, 1999.

ANTAKI, C.;

WIDDICOMBE, S.

Identities in talk. London: Sage Publications, 1998.

ASHFORTH, B.;

MAEL, F.

Social identity theory and the organizational. Academy of Management Review, n. 14, p. 20-39, 1989.
Organizational identity and strategy as a context for the individual.

Strategy

Management, n. 13, p.19-64, 1996.

BAUDRILLARD, Y.;

GUILLAUME, M.

Figures de l'altérité. Paris:

Descartes \& Cie, 1994.

BAUGNET, L.

L'identité sociale. Dunod: Paris, 1998. 
BELLE, F.

Cultura de empresa e identidades profissionais. Revista de Administração, n. 2, p. 40-59, 1991.

\section{BORDIEU, P.}

L'identité et la réprésentation éléments pour une reflexion critique sur l'idée de region. Actes de la recherche en sciences sociales, n. 35, p. 63-72, 1980.

BROWN, A.

Narcissism, identity and legitimacy. Academy of Management, n. 22, p. 643-686, 1997.

BROWN, A.;

STARKEY, K.

Organizational identity and learning: a psychodynamic perspective. The Academy of Management Review, v. 25, n. 1, p. 102-118, 2000.

CANDAU, J.

Mémoire et identité. Paris: Presses Universitaires de France, 1998.

CASTELLS, M.

$O$ poder da identidade. São Paulo: Paz e Terra, 1999.

CHAUCHAT, H.;

DURAND-DELVIGNE, A.

De l'identité du sujet au lien social. Paris : Presses Universitaires de France, 1999.
CHODOROW, N. J.

Feminism and psychoanalytic theory. London: Yale University Press, 1989.

CIAMPA, C. et al.

Psicologia social: o homem em movimento. São Paulo: Brasiliense, 1997.

CLEGG, S.; HARDY, C.;

NORD, W.

Handbook de estudos organizacionais. São Paulo: Atlas, 1999. v. 1.

CRAIB, I.

Experiencing identity. London: Sage Publications, 1998.

CUCHE, D.

La notion de culture dans les sciences sociales. Paris: La Decouverte, 1996.

DAVEL, E.;

MACHADO, H. V.

A dinâmica entre liderança e identificação: sobre a influência consentida nas organizações contemporâneas. Revista de Administração Contemporânea, v. 5, n. 3, p. 107-126, 2001.

DEETZ, S.

The micro-politics of identity formation in the workplace: the case of a knowledge intensive form. Human Studies, n. 17, p. 23-44,1994. 
DESCHAMPS, J. C. et al.

Vies sociales: 1'identité sociale la construction de l'individu dans les relations entre groupes. Grenoble: Presses Universitaires de Grenoble, 1999.

DUBAR, C.

La socialisation: construction des identités sociales et professionnelles. 2.ed. Paris: Armand Colin, 1996.

DUTTON, J. E.;

DUKERICH, J. M.

Keeping an eye on the mirror: image and identity in organizational adaptation. Academy of Management Journal, v. 34, n. 3, p. 517-554, 1991.

DUTTON, J. E.;

DUKERICH, J. M.; HARQUAIL, C. V. Organizational images and member identifications. Administrative Science Quarterly, n. 259, 1994.

\section{EPSTEIN, S.}

The self-concept: a review and the proposal of an integrated theory of personality. In: STRAUB, E. Personality, basic aspects and current research. Englewood Cliffs, NJ: Prentice Hall, 1980.

ERICKSON, E. H.

Identity and the life cycle. London: W. W. Norton \& Company, 1994.
FERRET, S.

L'identité. Paris: Corpus Flammarion, 1998.

\section{GIDDENS, A.}

Modernity and self-identity: self and society in the life modern age. California: Stanford University Press, 1991.

\section{GIOIA, D.}

From individual to organizational identity. In: WHETTEN, D.; GODFREY, P. Identity in organizations. London: Sage Publications, 1998.

GIOIA, D.;

SCHULTZ, M.;

CORLEY, $\mathrm{K}$.

Organizational identity, image and adaptive instability. The Academy of Management Review, n. 25, 1, p. 63-81, 2000.

GOFFMAN, E.

Estigma: notas sobre a manipulação da identidade deteriorada. 4.ed. Rio de Janeiro: Editora Guanabara, 1988.

HAVILAND, J. M. et al.

The place of emotion in identity. Journal of Research on Adolescence, n. 4, p. 503-18, 1994.

HOCHSCHILD, A. R.

The managed heart commercialization of human feeling. California: University of California Press, 1983. 
HOELTER, J. W.

The structure of self conception: conceptualization and measurement. Journal of Personality and Social Psychology, v. 49, n. 5, p. 13921407, 1985.

HOGG, M.;

TERRY, D.

Social identity and selfcategorization processes in organizational context. Academy of Management Review, v. 25, n. 1, p. 121-140, 2000.

HOLMER-NADESON, M.

Organizational identity and space of action. Organizational Studies, v. 17, n. 1, p. 49-81, 1996.

HOWARD, J. A.

Social psychology of identities. Annual Review of Sociology, n. 26, p. 367-393, 2000.

JO HATCH, M.;

SCHULTZ, M.

Relation between organizational culture, identity and image. European Journal of Marketing, v. 31, n. 5/6, p. 356365, 1997.

KAGAN, J.

The concept of identification.

Psychology Review, v. 65, n. 5, p. 96-305, 1958.

LÉVI-STRAUSS, C.

L'identité. Paris: Presses Universitaires de France, 1977.
LINDESMITH, A.;

STRAUSS, A.;

DENZIN, N.

Social psychology. 8.ed. London: Sage Publications, 1999.

MACHADO, H. V.

Aposentadas e empreendedoras. In: CONGRESSO DE CIÊNCIAS HUMANAS, LETRAS E ARTES, IV., 1999, Viçosa. Anais... Viçosa: Universidade Federal de Minas Gerais, 1999.

Becoming entrepreneurs from identification's pattern. In: ICSB WORLD CONFERENCE, 2001, Taipei. Proceedings... Taipei: [s.n.], 2001.

MACHADO-DA-SILVA, C. L.; NOGUEIRA, E. E.

Identidade organizacional: um caso de manutenção, outro de mudança. Revista de Administração Contemporânea, p. 35-58, 2001. Edição especial.

MAEL, F.;

ASHFORTH, B. E.

Alumni and their alma mater: a partial test of the reformulated model of organizational identification. Journal of Organizational Behavior, n. 13, p. 103-123, 1992.

MAFFESSOLI, M.

No fundo das aparências. Petrópolis: Vozes, 1996. 
O tempo das tribos. 2.ed. São Paulo: Forense Universitária, 1998.

L'instant eternel. Paris: Denöel, 2000.

MARKUS, H.;

NURIUS, $\mathrm{P}$.

Possible selves. American Psychologist, v. 41, n. 9, p.54-969, 1986.

MIRANDA, C.

Identidade: síntese das múltiplas identificações. São Paulo: Cabral Editora Universitária, 1998.

\section{MOESSINGER, $\mathrm{P}$.}

Le jeu de l'identité. Paris: Presses Universitaires de France, 2000.

NKOMO, S.;

COX, T.

Diversidade e identidade nas organizações. In: CLEGG, S.; HARDY, C.; NORD, W. Handbook de estudos organizacionais. São Paulo: Atlas, 1999. v. 1.

PAHL, R.

Depois do sucesso: ansiedade e identidade fin-de-siècle. São Paulo: Editora Unesp, 1997.

PALMADE, J.

Postmodernité et fragilité identitaire. Connexions, v. 55, n. 1, p. 8-27, 1990.
PAVLICA, K.;

THORPE, R.

Managers perceptions of their Identity: a comparative study between the Czech Republic and Britain. British Journal of Management, v. 9, p. 133-149, 1998.

PLACER, F. C.

Identidade, diferença e indeferência: o si mesmo como obstáculo. In: LARROSA, J.; LARA, N. Imagens do outro. Petrópolis: Vozes, 1998.

PRATT, M. G.

The good, the bad and the ambivalent: managing identification among Amway Distributors. Administrative Science Quarterly, p. 456-498, 2000.

PRATT, M. G.;

FOREMAN, P. O.

Classifying managerial responses to multiple organizational identities. The Academy of Management Review, v. 25, 1, p. 18-42, 2000.

RICOUER, P.

O si mesmo como um outro. São Paulo: Papirus, 1990.

ROULEAU, L.

A dificuldade do gerente intermediário no contexto de reorganização: rompimento e renovações identitárias. Revista de Estudos Organizacionais, v. 2, n. 2, p. 11-22, 2001. 
RUANO-BORBALAN, J.

L'Identité: l'individu, le groupe, la société. Paris: Éditions Sciences Humaines, 1998.

SAINSANLIEU, R.

Identité au travail les effets culturels de l'organisation. Paris: Presses de la Fondation Nationale de Sciences Politiques, 1977.

L'identité au travail: une expérience partagée. In: FRANCFORT, J. et al. Les mondes sociaux de l'entreprise. Paris: Sociologie Économique, 1995.

SCOTT; LANE.

A stakeholder approach to organizational identity. Academy of Management Review, v. 25, n. 1, p. 43-62, 2000.

SLATER, P. E.

Toward a dualistic theory of identification. Merrill-Palmer Quarterly, v. 7, n. 2, p. 113-126, 1961.

TAJFEL, H.;

TURNER, J. C.

The social identity theory of inter group behavior. In: WRCHEL, S.;
AUSTIN, W. G. Psychology of inter group relations. Chicago: Nelson-Hale Publishers, 1986.

TURNBULL, S.

Corporate ideology: meanings and contradictions for middle managers. British Journal of Management, v. 12, p. 231-242, 2001.

TURNER, R. H.

The self-conception in social interaction. In: GORDON, C.; GERGEN, K. J. The self in social interaction. New York: Wiley, 1968.

WHETTEN, D.;

GODFREY, P.

Identity in organizations.

London: Sage Publications, 1998.

WORCHEL, S.

Social identity and individual productivity within groups. British Journal of Social Psychology, n. 37, p. 389-413, 1998.

WORCHEL, S.;

AUSTIN, W.

Psychology of inter group relations. Chicago: Nelson-Hall Publishers, 1986. 